Revista de Antropología Social

ISSN: 1131-558X

http://dx.doi.org/10.5209/rev_RASO.2016.v25.n1.52633

\title{
Desaparecer de sí mismo
}

Eguzki Urteaga ${ }^{1}$

LE BRETON, David. 2015. Disparaître de soi. Une tentation contemporaine. París: Métailié.

El sociólogo y antropólogo David Le Breton acaba de publicar su última obra titulada Disparaître de soi. Une tentation contemporaine (Desaparecer de sí mismo. Una tentación contemporánea) en la colección Traversées de la editorial Métailié. Conviene recordar que este investigador galo es catedrático de sociología por la Universidad de Estrasburgo, miembro del Instituto de Francia y socio del Instituto de Estudios Avanzados de dicha Universidad (USIAS). Especialista de las representaciones y transformaciones del cuerpo humano, que ha estudiado a través de las conductas de riesgo, es autor de numerosos obras entre las cuales podemos citar L'Adieu au corps (1999), Expériences de la douleur (2000), Conduites à risques (2002) o Signes d'identité (2002). Asimismo, ha participado en numerosas libros colectivos y ha dirigido varios monográficos de revistas tales como Autrement, Revue des Sciences Sociales o Cultures et Sociétés. Además de sus actividades editoriales como director de colección en Armand Colin y Belin, forma parte del comité editorial de múltiples revistas tanto en Francia como en el extranjero.

En su último libro, Le Breton se centra en la tentación creciente de las personas actuales de desaparecer de sí mismas para poder descansar ante el agotamiento que genera la vida social. Esto se produce en un contexto en el cual "nuestras existencias nos pesan. Incluso por un tiempo, nos gustaría escapar de las obligaciones que les están vinculadas" (Le Breton, 2015: 13). La fragmentación del vínculo social "aísla a cada individuo y lo enfrenta a su libertad, al disfrute de su autonomía o, al contrario, a su sentimiento de insuficiencia, a su fracaso personal" (2015: 13). El autor considera que el individuo carente de autoestima y de sólidos recursos personales, que le permitan adaptarse a las situaciones e invertir los acontecimientos de significados y valores, se siente vulnerable, lo que genera "un clima de tensión, preocupación, duda y dificultad" (2015: 13). Ante esa situación, numerosas personas aspiran a desprenderse de la presión que pesa sobre sus hombros y a suspender el esfuerzo que es preciso realizar para continuar siendo sí mismo y estar a la altura de las circunstancias (2015: 13-14).

Prosiguiendo su radiografía de las identidades contemporáneas, subraya que, en una sociedad en la que prevalece la flexibilidad, la urgencia, la velocidad, la competencia y la búsqueda de eficacia, ser uno mismo no constituye ninguna evidencia, dado que es preciso, constantemente y sin posibilidad de escape, estar en

Universidad del País Vasco

eguzki.urteaga@ehu.es 
el mundo, estar relacionado con los demás, adaptarse a los acontecimientos y asumir su autonomía, lo que resulta cansino en numerosas casos. La época actual implica "construirse constantemente, estar movilizado, dar un sentido a su vida, basar sus acciones en valores" (2015: 14) así como renovar periódicamente sus recursos propios y esforzarse constantemente en evitar el desasosiego.

En ese contexto, la relajación del esfuerzo que exige ser sí mismo es una tentación creciente. De hecho, el individuo contemporáneo necesita a veces alejarse de los demás y aprovechar ciertos momentos de la vida diaria para abstraerse de las exigencias que impone la comunicación social. Esta ausencia es un aspecto esencial de la vida diaria que conduce a un olvido momentáneo del entorno y a un abandono provisional de la voluntad. Según Le Breton, esta ausencia responde "a una sensación de saturación, a un exceso experimentado por el individuo" (2015: 17-18). A veces, la depresión, el burn out o el aislamiento voluntario traducen ese malestar y pueden llevar a dejarse llevar y a renunciar a su ego. De manera general, ese abandono de sí mismo afecta a cualquier persona que, momentáneamente o de manera más duradera, agota los recursos íntimos que le permiten asumir su personaje social.

En la primera parte del libro, Le Breton subraya que ciertas "historias personales, una ruptura particular, una separación, un duelo, un despido, un hastío conducen a desprenderse poco a poco de sí mismo" (2015: 23). Aludiendo a autores (Pessoa, Auster, Melville), personajes literarios (Bartleby, Oblomov) y figuras históricas (Lawrence de Arabia), ilustra cuatro formas radicales de desprendimiento de uno mismo, que son la vida impersonal, la indiferencia, la multiplicación y la desaparición.

Así, en la vida impersonal, el desapego hacía sí mismo responde a una voluntad de ralentizar o de parar el flujo del pensamiento y de poner fin a la necesidad social de jugar constantemente un rol que se adecue a las situaciones y a los interlocutores (2015: 25). La indiferencia, por su parte, traduce una voluntad de no colaborar con los demás o de mantenerse a distancia de las interacciones, lo que se transforma en una suerte de neutralización radical de cualquier afectividad y en una desvitalización que va más allá de la ligera reserva que exige la vida social (2015: 35). La indiferencia "es una forma de ataraxia epicúrea o de apatía estoica" (2015: 36). En cuanto a la multiplicación, es a menudo el hecho de artistas en general y de escritores en particular que tienen la posibilidad de deshacerse de sí mismos multiplicando los personajes de ficción, escogiendo pseudónimos o conjugando las posibilidades de ser uno mismo gracias a heterónimos (2015: 43). Por último, la desaparición puede ser una solución al agotamiento que implica ser sí mismo y a la sensación de haberlo dado todo, o responde a la voluntad de mantenerse en la reserva o en la soledad (2015: 47). Es "una expresión radical de la libertad o del rechazo de colaborar, manteniéndose a distancia o sustrayéndose a la parte más coactiva del vínculo social" (2015: 50).

En la segunda parte de la obra, el sociólogo galo analiza las "maneras discretas de desaparecer", tales como el sueño, el burn out o la depresión. Así, el sueño es una forma de escapar a la dificultad de ser uno mismo (2015: 51), ya que permite escapar de sus responsabilidades y del imperativo de ser activo. Como lo dice Le Breton, "el sueño cierra el mundo a su alrededor" (2015: 52), se convierte en un refugio y en una manera de dar la espalda a los imperativos del mundo. A su vez, el sueño es una declinación de la ausencia y puede ser igualmente una forma de pensar y de recobrar fuerzas (2015: 55). De la misma manera, el burn out provoca un cansancio y una desmotivación en la persona que se consume lentamente en el trabajo. Este último se convierte en sufrimiento y en destrucción de la subjetividad (2015: 65). A su vez, la 
depresión, que constituye otra manera discreta de desaparecer, resulta del agotamiento provocado por la necesidad de mantenerse a nivel de las exigencias requeridas por sí mismo y por el entorno. En la actualidad, "el individuo debe constantemente dar cuenta de su capacidad a actuar por sí mismo" (2015: 68) y de construir su propia experiencia, de modo que la depresión rompa la confianza en sí mismo y la autoestima de la persona (2015: 71). Por último, la inmersión apasionada en una actividad, tanto laboral como de ocio, es una forma de oponer a la incertidumbre de las relaciones sociales una relación constante que orienta totalmente la existencia de la persona (2015: 78).

Una vez analizadas las formas radicales o más discretas de desaparición de uno mismo, el autor se centra, en la tercera parte de su obra, en los adolescentes que han sido objeto de estudios anteriores de Le Breton (Le Breton, 2002c; 2007; Le Breton et al., 2005). Muestra cómo dicha desaparición es una manera de ocultar las coacciones impuestas por la identidad social, ofrece una oportunidad de vagabundear y permite desprenderse de sí mismo en la esfera virtual (2015: 94). De la misma forma, los adolescentes experimentan la desaparición vía la identificación con otra persona, que es a menudo un cantante o un actor famoso, pero también a través de la anorexia (2015: 108) que se traduce por una transformación radical del cuerpo que acaba siendo irreconocible. Los fenómenos de pérdida de conciencia y de control como consecuencia del consumo de alcohol, de drogas o de productos psicoactivos son igualmente muestras de esta aspiración a desaparecer. Pero, la forma más clara de esa voluntad es la fuga del domicilio familiar para un periodo más o menos largo.

En la cuarta parte del libro, Le Breton se interesa por la desaparición de sí mismo que experimentan las personas mayores, las pacientes de Alzheimer y los enfermos en fase terminal. En efecto, si el envejecimiento es vivido a menudo como una renovación de las tareas y de los placeres, es igualmente una prueba porque dificulta la continuidad del sentimiento de sí mismo y la calidad de la implicación en el mundo. "Se transforma en una lenta desaparición al ver disminuir sus fuerzas (...). El cuerpo pierde su evidencia (...). Cambia poco a poco, y es difícil a veces reconocerse en él, la cara se convierte en extraña y la disminución de las capacidades contribuye a una relajación de sí mismo" (2015: 136). Más aún, el propio sujeto desaparece, como acontece en las diferentes formas de demencia senil, a imagen de la enfermedad de Alzheimer. En este caso, la desconexión con el mundo, la ruptura con el pasado y el no reconocimiento de uno mismo alcanzan un nivel extremo (2015: 143). A menudo la degeneración es progresiva, de modo que la persona es plenamente consciente de su decadencia. Por último, cuando la demencia alcanza cierto grado se convierte en un estatus que dificulta e incluso imposibilita cualquier forma de evolución positiva. El tratamiento socio-sanitario encierra la persona en su destino (2015: 154) y ésta carece de medios y de oportunidades para modificarlo.

En la quinta parte del libro, titulada "desaparecer sin dejar una dirección", el autor considera que una estancia en otro lugar, durante las vacaciones o un viaje, confiere una dimensión geográfica a la desaparición de sí mismo. Se trata de una forma atenuada de deshacerse durante días o semanas de las exigencias de la vida profesional, personal y familiar (2015: 157). En ese sentido, "el viaje es un ejercicio de desaparición de sí mismo" (2015: 158). Ese paréntesis es una suerte de recreo social donde los roles sociales dejan de regir la vida diaria en beneficio de una breve libertad. Porque "la liberación de la mirada de los demás que gravitan en la esfera de conocidos relaja las imposiciones del estatus", sabiendo que, en la vida diaria, "es 
difícil deshacerse de su posición social, de las relaciones de amistad o de vecindario, de los lazos familiares" (2015: 158), etc. Pero, la desaparición puede durar y el viaje puede transformarse en instalación definitiva, ofreciendo una posibilidad de renacimiento personal y social. Esa desaparición implica una organización minuciosa para no dejar rastro y no correr el riesgo de ser reencontrado rápidamente (2015: 165). Le Breton subraya que existen numerosos sitios Internet especializados en asesorar a las personas para que puedan desaparecer eficazmente y empezar una nueva vida en otro lugar (2015: 166).

En definitiva, en un contexto marcado por el auge del individualismo en las sociedades contemporáneas, en un mundo en el cual es preciso decidir constantemente sobre sí mismo y sus valores, sin que el vínculo social ampare sus decisiones, la libertad se convierte en un vértigo y el sentido de relatividad de la existencia impregna la experiencia subjetiva (2015: 176). La tentación de desaparición de sí mismo aumenta notablemente porque es cada vez más difícil ser un individuo plenamente realizado, sean cuales sean los estatus sociales y las referencias culturales de las personas. En ese sentido, a lo largo de este libro, el autor sigue las pistas múltiples de la desaparición de uno mismo, "las estratagemas de los individuos contemporáneos para deslizarse entre las mallas del tejido social y renacer en otro lugar bajo otra versión o desaparecer en la discreción, la soledad, la ausencia" (2015: 193). Figuras felices e infelices se suceden a lo largo de las páginas. De hecho, liberada de las tradiciones y de las costumbres, cada persona se convierte en su propia dueña y solo debe rendir cuentas a sí misma (2015: 13). No obstante, todos los individuos no gozan de las mismas capacidades para ser un sujeto (2015: 14).

$\mathrm{Al}$ término de la lectura de Disparaittre de soi. Une tentation contemporaine, el lector tiene la convicción íntima de que Le Breton ha realizado una lectura pertinente y minuciosa de la identidad individual en las sociedades contemporáneas, de sus dificultades y de sus aspiraciones profundas, entre las cuales figura el deseo de desaparecer de sí mismo. Compaginando una perspectiva analítica, vía ambas tipologías de las maneras radicales o más discretas de desaparecer, con estudios empíricos ilustrados por ejemplos extraídos de la actualidad y de la literatura, el autor ofrece une visión sistematizada y precisa del objeto de estudio. Evita caer en una representación patológica y extrema de dicha tentación, sin ocultar por ello su variedad, dando a entender que la voluntad de desaparecer es ampliamente compartida, aunque tome diferentes formas, que van del cambio de vivienda o de la dimisión de su empleo, al traslado a otro país, pasando por la separación de su pareja (2015: 163). Pero, como lo subraya el autor, en la mayoría de los casos, los individuos necesitan alejarse momentáneamente de los demás para descansar, recobrar fuerzas y volver fortalecidos a la vida social. No en vano, y de cara a matizar la valoración positiva que merece ese libro, cabe señalar que el capítulo titulado "Sí mismo como ficción", donde Le Breton analiza la identidad como proceso y como fragilidad, no aporta nada a la demostración y hubiese podido perfectamente ser suprimido sin que perjudique la comprensión de la obra.

En cualquier caso, la lectura del último libro de este sociólogo original y perspicaz se antoja ineludible para cualquier investigador, pensador u observador deseoso de comprender los entresijos de la hiper-modernidad y los dilemas que plantea. 


\section{Referencias bibliográficas}

Le Breton, David (1999). L’Adieu du corps. París: Métailié.

- (2002a). Conduites à risque. París: PUF.

- (2002b). Signes d'identité. Tatouages, piercings et autres marques corporelles. París: Métailié.

- (2002c). L'adolescence à risque. París: Autrement.

- (2007). En souffrance. Adolescence et entrée dans la vie. París: Métailié.

- (2010). Expériences de la douleur. París: Métailié.

- (2015). Disparaître de soi. Une tentation contemporaine. París: Métailié.

Le Breton, David et al. (2005). Jeunesse à risque. Rite et passage. Québec: Presses de l’Université Laval. 